UNIVERSIDADE DE SÃO PAULO ESCOLA DE COMUNICAÇÃO E ARTES PROGRAMA DE PÓS-GRADUAÇÃO EM COMUNICAÇÃO SOCIAL

\title{
DANI GURGEL
}

\section{A IMAGEM DO MÚSICO EM CO-AUTORIA COM SEU PÚBLICO}

UMA ANÁLISE DA PRODUÇÃO AMADORA DE IMAGENS ATRAVÉS DA ÓTICA DE SETE ARTISTAS INDEPENDENTES E SEUS FÃS

\section{[VERSÃO RESUMIDA]}

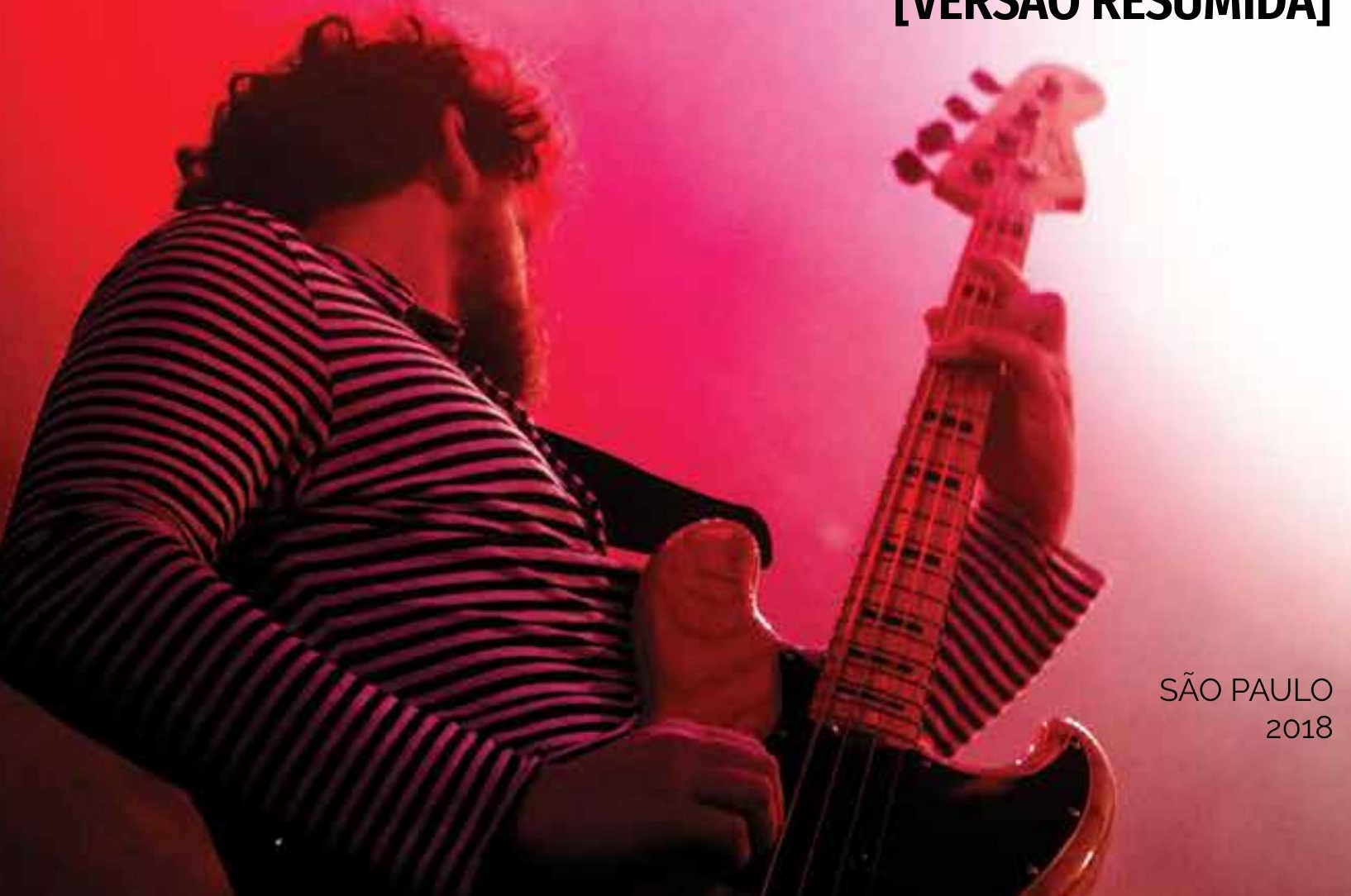


Versão resumida para publicação temporária na base de Teses da USP. A numeração de páginas segue a numeração original.

Contato da autora:

contato@danigurgel.com.br http://www.danigurgel.com.br 
UNIVERSIDADE DE SÃO PAULO

ESCOLA DE COMUNICAÇÃO E ARTES

PROGRAMA DE PÓS-GRADUAÇÃO EM COMUNICAÇÃO SOCIAL

\section{DANI GURGEL}

\section{A IMAGEM DO MÚSICO EM CO-AUTORIA COM SEU PÚBLICO}

Uma análise da produção amadora de imagens através da ótica de sete artistas independentes e seus fãs. [versão resumida]

Dissertação apresentada ao Programa de Pós Graduação em Comunicação Social, Escola de Comunicações e Artes, Universidade de São Paulo, como requisito parcial à obtenção do título de Mestre em Comunicação Social.

Orientador: Prof. Dr. Luli Radfahrer.

São Paulo 2018 
Este trabalho é licenciado para uso não-comercial com crédito à autora e mediante compartilhamento sob a mesma licença, através do Creative Commons.

\section{cc) (i) (2) (2) \\ BY NC SA}

As imagens são de propriedade dos autores, indicados em suas legendas.

Catalogação na Publicação

Serviço de Biblioteca e Documentação

Escola de Comunicações e Artes da Universidade de São Paulo

Dados inseridos pela autora

Gurgel, Dani

A Imagem do músico em co-autoria com seu público: Uma análise da produção amadora de imagens através da ótica de sete artistas independentes e seus fã̃s / Dani Gurgel. -- São Paulo: D. Gurgel, 2018.

3i6 p.: il.

Dissertação (Mestrado) - Programa de Pós-Graduação em Ciências da Comunicação - Escola de Comunicações e Artes / Universidade de São Paulo.

Orientador: Luiz Guilherme de Carvalho Antunes

Bibliografia

I. Indústria Cultural 2. Música 3. Comunicação Digital 4. Audiovisual I. Antunes, Luiz Guilherme de Carvalho II. Título. III. Gurgel, Daniela Picarelli do Amaral

CDD 2r.ed. - 306

Elaborado por Sarah Lorenzon Ferreira - CRB-8/6888 


\section{FOLHADEAPROVAÇÃO}

GURGEL, Dani. A Imagem do músico em co-autoria com seu público: Uma análise da produção amadora de imagens através da ótica de sete artistas independentes e seus fãs. 20I8. 316 p. Dissertação (Mestrado) - Escola de Comunicações e Artes, Universidade de São Paulo, São Paulo, 2018.

Dissertação apresentada ao Programa de Pós Graduação em Comunicação Social, Escola de Comunicações e Artes, Universidade de São Paulo, como requisito parcial à obtenção do título de Mestre.

Aprovada em:

Banca examinadora

Prof. Dr.: Instituição:

Julgamento: Assinatura:

Prof. Dr: Instituição:

Julgamento: Assinatura:

Prof. Dr:: Instituição:

Julgamento: Assinatura:

Prof. Dr:: Luiz Guilherme de Carvalho Antunes Instituição:ECA-USP [Orientador] Assinatura: 
GURGEL, Dani. A Imagem do músico em co-autoria com seu público: Uma análise da produção amadora de imagens através da ótica de sete artistas independentes e seus fã̃s. 2018. 316 p. Dissertação (Mestrado) - Escola de Comunicações e Artes, Universidade de São Paulo, São Paulo, 2018. 


\section{RESUMO}

As formas de se criar e compartilhar música e imagem se encontram em constante revolução, propiciada pelas novas possibilidades de produção e divulgação de conteúdo. Artistas e público interagem de maneiras criativas e oportunas com esse novo ambiente, enquanto a comunicação como um todo traça um caminho de volta à oralidade na transmissão de conhecimento.

É objetivo deste trabalho identificar a importância do conteúdo amador para a divulgação de artistas independentes, em especial no site de vídeos YouTube. Conteúdo esse que é produzido em duas frentes: o público contribui com versões cover, homenagens, registros da plateia de shows, aulas de violão, karaokês e conteúdo original republicado sem autorização; e os artistas oferecem suas cenas de bastidores, novas composições, apresentações ao vivo e participações; entremeadas com seu conteúdo de lançamento comercial - como videoclipes e álbuns.

A oralidade secundária que segue o fechamento do Parêntese de Gutenberg, apresentado por Thomas Pettit, traz um novo meio de se conhecer, ouvir, tocar e compartilhar música, especialmente através desse conteúdo amador. Artistas são apresentados por seu próprio público, que relê e reescreve as canções a seu modo, registra e reporta seus acontecimentos com sua própria estética, e realimenta sua produção com seus próprios desejos.

Para tanto, sete artistas independentes foram analisados quantitativamente e posteriormente entrevistados quanto a seu faturamento, execução pública e presença no YouTube. Por último, foi proposto um experimento imagético com a participação do público de uma apresentação musical de um dos artistas em questão, cujos resultados foram comparados aos de um experimento similar conduzido dez anos antes.

\section{PALAVRAS-CHAVE}

Música; Fotografia; Vídeo; Prossumidor; Amador 
GURGEL, Dani. Musicians and their audience, partners in creating the artist's public image: An analysis of the amateur content through the point of view of seven independent artists and their fans. 20I8. 316 p. Dissertation (Master of Science) - Escola de Comunicações e Artes, Universidade de São Paulo, São Paulo, 20 I8. 


\section{ABSTRACT}

The ways in which music and image are created and shared are in constant revolution, caused by the new possibilities of producing and disseminating content. Artists and audience take part in creative opportunities for dealing with this new environment, as communication as a whole traces its path back to orality.

The purpose of this thesis is to identify the relevance of amateur content on the promotion of independent musical artists, especially through the video website YouTube. Fans share their cover versions, tributes, concert videos, guitar lessons, karaoke animations and original ripped content; while artists share their backstage scenes, rehearsals, new compositions, live performances, special guests along with their official commercial releases of tracks and music videos.

The secondary orality that follows the closing of The Gutenberg Parenthesis, presented by Thomas Pettit, brings new ways to get to know, listen to, play and share music, especially through the amateur content. Artists are introduced by their own audiences, who re-read and re-write their music in their own way. Fans document and report the artist happenings in their own aesthetics and refuel their production with their own desires.

For that purpose, seven independent artists have been quantitatively analysed and subsequently interviewed about their revenue, broadcasts and YouTube presence. At last, an audiovisual experiment was conducted, in which a live music concert was photographed and recorded on video by amateur guests. Their outcome was compared to that of a similar experiment conducted ten years before.

\section{KEYWORDS}

Music; Photography; Video; Prosumer; Amateur 


\section{SUMÁRIO}

1. INTRODUÇÃO

2. INDÚSTRIA MUSICAL 35

2.1 SELOS, GRAVADORAS E MÚSICOS INDEPENDENTES 37

2.2 UM NOVO PÚBLICO 41

2.3 O SUSTENTO DO MÚSICO $\quad 47$

$\begin{array}{lll}2.3 .1 & \text { Atividades musicais } & 48\end{array}$

$\begin{array}{lll}2.3 .1 .1 & \text { Autor } & 48\end{array}$

$\begin{array}{lll}2.3 .1 .2 & \text { Fonograma } & 49\end{array}$

2.3.1.3 Performance 50

2.3.2 Alguns conceitos da indústria musical 51

2.3.2.1 Contrato de 360 graus 51

2.3.2.2 ISRC

2.3.3 Quais são as fontes de renda do músico?

2.3.3.1 Distribuição das fontes na renda 56

2.4 NOVAS E ANTIGAS FORMAS DE COMERCIALIZAÇÃO DE MÚSICA 59

2.4.1 A Comercialização do fonograma $\quad 59$

$\begin{array}{lll}\text { 2.4.1.1 Lojas online } & 61\end{array}$

$\begin{array}{ll}\text { 2.4.1.2 Diversificação } & 62\end{array}$

$\begin{array}{lll}\text { 2.4.1.3 Streaming } & 63\end{array}$

2.4.1.4 Plataformas com conteúdo não-oficial 69

2.4.1.5 Fonogramas no YouTube, Content ID, Vevo 70

$\begin{array}{ll}\text { 2.4.1.6 Outros mercados: Japão } & 73\end{array}$ 


$\begin{array}{llll} & \text { 2.4.1.7 } & \text { Download gratuito } & 74 \\ & 2.4 .1 .8 & \text { Creative Commons } & 76 \\ & 2.4 .1 .9 & \text { O download está obsoleto? Dados do podcast "Música de Graça" } & 79 \\ 2.4 .2 & \text { Shows } & 83 \\ 2.4 .3 & \text { Execução pública } & 84 \\ & \text { 2.4.3.1 } \quad \text { A distribuição mais democrática no ECAD } & 86 \\ 2.4 .4 & \text { Os direitos autorais dentro do fonograma } & 87 \\ & & 88\end{array}$

2.5 QUEM É O PÚBLICO? $\quad 91$

3. VÍDEO, AMADOR, FÃ 95

$\begin{array}{lll}3.1 & \text { A VISUALIDADE DA MÚSICA } & 97\end{array}$

3.2 AMADOR, PROSSUMIDOR E O YOUTUBE 103

$\begin{array}{lll}\text { 3.2.1 Música amadora } & 103\end{array}$

$\begin{array}{lll}\text { 3.2.2 Prossumidores } & 104\end{array}$

$\begin{array}{lll}\text { 3.2.3 Imagem amadora } & 106\end{array}$

$\begin{array}{lll}\text { 3.2.3.1 Equipamentos } & 107\end{array}$

$\begin{array}{ll}\text { 3.2.3.2 Baixa profundidade de campo } & 108\end{array}$

$\begin{array}{lll}3.2 .4 & \text { Áudio } & 110\end{array}$

3.2.4.1 Áudio amador 111

3.2.5 Amadores no YouTube 114

$\begin{array}{ll}3.3 & \text { O FÃ DE MÚSICA } \\ \end{array}$

4. SETE ARTISTAS INDEPENDENTES 125

$\begin{array}{lll}4.1 & \text { FATURAMENTO: A DISTRIBUIDORA TRATORE } & 128\end{array}$

$\begin{array}{lll}4.1 .1 & \text { Proveniência } & 128\end{array}$ 
4.1.2 Metodologia para aquisição de dados 128

4.1.3 Metodologia para o tratamento dos dados 130

$\begin{array}{lll}\text { 4.1.3.1 Dados originais } & 130\end{array}$

4.1.3.2 Distribuição percentual entre lojas 132

4.1.3.3 Identificação das 5 principais lojas, por artista 133

4.1.3.4 Identificação do tipo das lojas 134

$\begin{array}{lll}\text { 4.1.3.5 Faturamento por tipo de serviço } & 135\end{array}$

4.1.3.6 Exceções - linhas negativas 136

4.1.4 Tabelas finais 140

$\begin{array}{ll}4.2 & \text { EXECUÇÃO PÚBLICA: PLAYAX }\end{array}$

$\begin{array}{lll}\text { 4.2.1 } & \text { Artistas } & 143\end{array}$

4.2.2 Metodologia para tratamento dos dados 144

4.2.2.1 Formatação dos dados originais $\quad 144$

$\begin{array}{lll}\text { 4.2.2.2 Contagem de execuções } & 145\end{array}$

$\begin{array}{ll}\text { 4.2.2.3 Contagem total } & 146\end{array}$

4.2.2.4 Transcrição por categoria 146

4.3 FATURAMENTO VERSUS EXECUÇÃO PÚBLICA

4.3.1 Escopo final 147

4.3.2 Diferenças conceituais entre os dados da Tratore, da Playax e do YouTube 149

4.3.3 Limitações dos dados obtidos 150

4.4 CANAIS DO YOUTUBE 152

4.4.1 Redes Multicanal e Content ID $\quad 154$

4.4.1.1 A métrica utilizada pelo Google 155

4.4.2 Videos com maior número de visualizações do canal 157

4.4.3 Videos com maior número de visualizações do artista em todo o YouTube 165

4.4.4 Os 30 vídeos com maior número de visualizações dos artistas no YouTube 173

4.4.5 Proporções entre as métricas dos canais e videos 176

$\begin{array}{lll}4.4 .6 & \text { Versões cover } & 178\end{array}$

$4.5 \quad$ ENTREVISTAS COM OS ARTISTAS 183

4.5.1 Objetivo, justificativa e metodologia 183 
4.5.2 Primeira fase: enumeração livre $\quad 185$

4.5.3 Segunda fase: quantitativa 196

4.5.4 Terceira fase: justificativas contra um consenso 201

4.6 "PRA VOCÊ DAR O NOME",

UMA CANÇÃO RESSIGNIFICADA ATRAVÉS DO YOUTUBE 208

4.7 CRUZAMENTO E CONSOLIDAÇÃO DE DADOS 216

$\begin{array}{lll}4.7 .1 & 5 \text { a Seco: versões cover } & 218\end{array}$

4.7.2 Dani Black: colaboração com outros artistas 220

4.7.3 Fabiana Cozza: shows e vendas físicas 222

4.7.4 Quarteto Quadrantes: 100\% oficial 224

$\begin{array}{lll}4.7 .5 & \text { Velhas Virgens: pirataria } & 226\end{array}$

4.7.6 Victor Biglione: conteúdo ripado 228

4.7.7 Vinicius Calderoni: videoclipes de um cineasta 229

4.8 CONSIDERAÇÕES SOBRE OS ARTISTAS ANALISADOS 233

5. FOTOGRAFIA AMADORA DE MÚSICA.

UM ESTUDO COMPARATIVO ENTRE 2007 E 2017

5.1 ANÁLISE QUANTITATIVA DAS IMAGENS $\quad 241$

$\begin{array}{lll}5.1 .1 & \text { Orientação } & 241\end{array}$

$\begin{array}{lll}5.1 .2 & \text { Video } & 247\end{array}$

$\begin{array}{lll}\text { 5.1.3 Tipos de câmeras } & 249\end{array}$

$\begin{array}{lll}5.1 .4 & \text { Reprises e filtros } & 252\end{array}$

5.1.5 Assuntos: público e ambiente versus selfies 256

5.2 TEMA VERSUS IMPROVISO 262

$\begin{array}{lll}5.3 & \text { NÓS VERSUS EU } & 277\end{array}$ 
Z. REFERÊNCIAS $\quad 289$

$\begin{array}{lll}7.1 & \text { JURISPRUDÊNCIA } & 295\end{array}$

8. ANEXOS 297

8.1 Transcrição integral das respostas à fase 1 da pesquisa Delphi 298

8.2 Transcrição integral das respostas à fase 3 da pesquisa Delphi 304

8.3 Transcrição integral da entrevista com Walter Venicio, do YouTube 311 


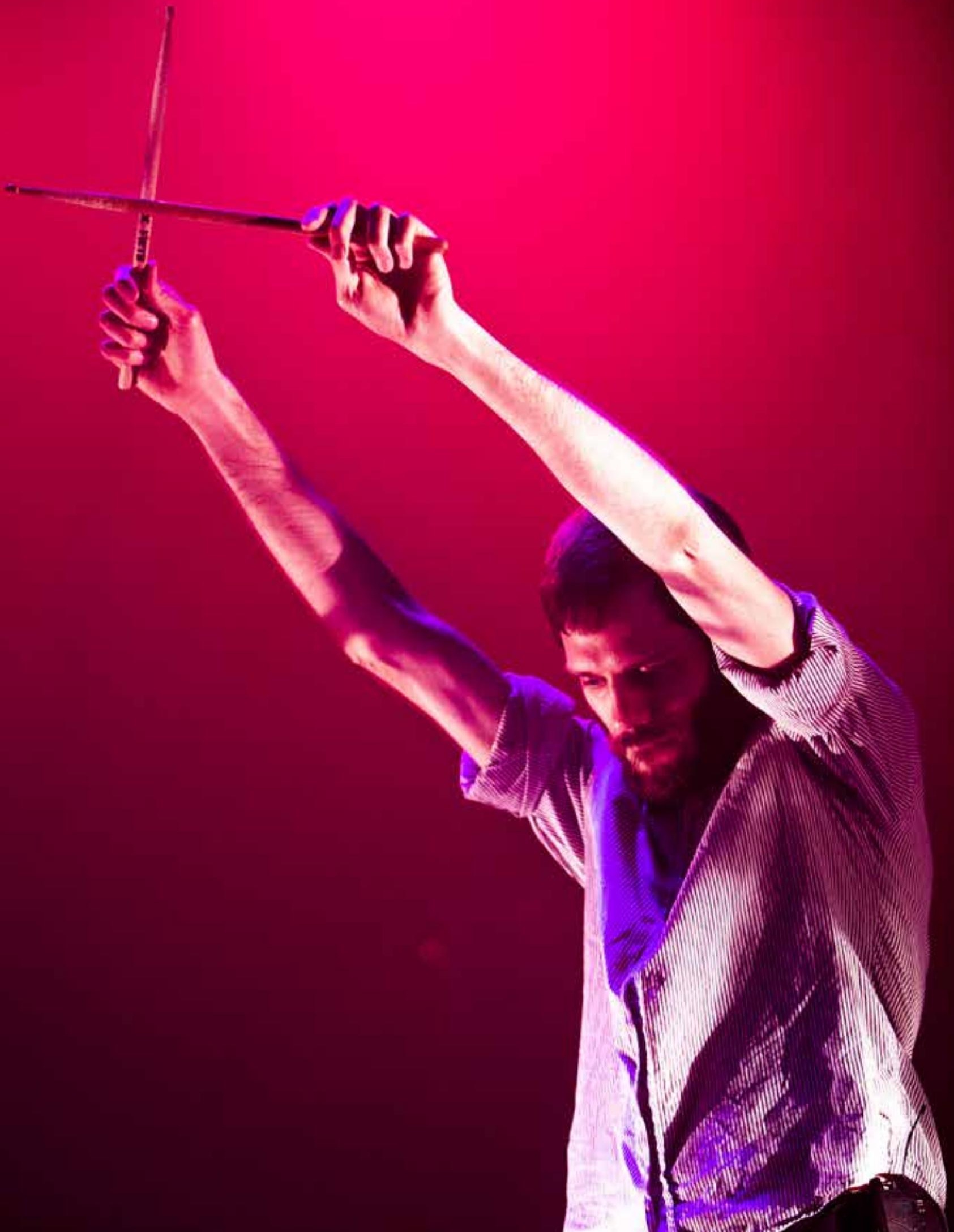






A indústria musical se encontra em constante revolução, sempre revendo os parâmetros que, poucas décadas antes, poderiam ser reconhecidos como regras de simples manutenção para os seus atores. No início do século XX, a invenção das máquinas de reprodução de sons, os fonógrafos, instigava discussões calorosas entre Figura I: Leo Bianchini, integrante do 5 a Seco, um dos artistas analisados nesta dissertação. Autora: compositores no congresso dos Estados Unidos, por mostrar o quão limitada era a lei do copyright até então, quando protegia apenas as partituras e não as obras musicais em si. O músico John Philip Sousa os chamava de "máquinas infernais" pois, segundo ele, seriam responsáveis por acabar com a música ao vivo (LESSIG, 20o8, I. Tradução livre de "infernal machines". p. 47-48). Em 1976, a indústria do cinema norte-americana, representada principalmente pelos estúdios Universal e Disney, processava a Sony pela criação do formato de gravação de vídeo BETAMAX. Sua alegação era a de que cerca de 9i\% do uso de aparelhos de gravação de vídeo era dedicado à gravação de conteúdo de direitos reservados (LESSIG, 2004, p. 75). 
2. Discos que funcionavam em 78 rotações por minuto, padrão da indústria na década de 1920 .

3. Tradução livre do original em inglês: "Everyday practice is less romantic than the pen of a public relations guru".

4. Artigo escrito por engenheiro que fez parte da equipe da Philips que desenvolveu o CD em parceria com a Sony, Dr. Kees A. Schouhamer Immink. No artigo, Immink aponta que a decisão foi tomada pela Sony em razão do diâmetro de r2omm, que resulta nos 74 minutos de duração, para não ficar em desvantagem, pois a Philips já tinha uma fábrica pronta e operacional para produzir o formato que ambas as partes haviam concordado anteriormente com II5mm e 60 minutos de duração.

5. Formato de arquivo cuja compressão permite uma versão aproximadamente dez vezes menor que um arquivo WAV (áudio não comprimido), o que facilita compartilhamento através da Internet.
Sempre moldada em torno do suporte no qual o áudio era registrado e vendido, a indústria musical foi transitando entre os formatos e deles absorvendo suas características: a duração de 3 a 4 minutos de uma canção comercial, herdada da capacidade máxima dos discos de $78 \mathrm{rpm}^{2}$; o álbum completo com aproximadamente 46 minutos, herdado da capacidade máxima de um disco de vinil; a criação de listas próprias de reprodução, iniciada com as fitas cassete; e a música como trilha sonora individual em fones de ouvido, inaugurada pelo walkman (VICENTE, 20I2, p. 203). Mesmo a duração de 74 minutos do CD, que poderia ser uma exceção - divulgada pelos fabricantes Philips e Sony como inspirada pela "Nona Sinfonia" de Beethoven-, foi desmentida por um de seus desenvolvedores como uma história "romântica" criada por "um guru de relações públicas”’3 para justificar uma decisão econômica (IMMINK, 2007, p. 45) ${ }^{4}$.

Seguindo essa lógica de mercado, em I98 I surge a emissora MTV, apresentando um conteúdo segmentado e estreito, com videoclipes do gênero rock'n roll (MUANIS, 2015, p. 6o). A emissora se posicionava como um novo formato para a música, que tinha perdido parte de seu público para uma geração mais interessada em televisão e videogames do que em "simplesmente" ouvir música (HOLZBACH, 20I4, p. 348-349), .

Em 2003, novamente a indústria musical se moldaria em busca de um novo suporte: era criada pela empresa Apple, fabricante dos populares tocadores digitais de música, os iPods, a iTunes Music Store, com o objetivo de vender música digital para um público que já tinha familiaridade com a manipulação de músicas em formato digital $\mathrm{MP}_{3}{ }^{5}$. Com esse movimento a indústria da música buscava responder à ameaça de então: a pirataria promovida pela mudança de suporte, o fácil armazenamento e, principalmente, a livre troca de faixas digitais através de plataformas como o Napster, programa de compartilhamento de arquivos lançado em i999. Segundo Sergio Amadeu da Silveira (2009, p. I6), "o fato de milhares de computadores que baixam um vídeo ou música tornarem-se simultaneamente distribuidores desse mesmo arquivo acelerou os fluxos e intensificou ainda mais as trocas digitais".

Considerando que a indústria da música é constantemente moldada e transformada por mudanças em seu formato de armazenamento e distribuição, cabe in- 
dagar se o objeto de suas vendas, ao invés da música (o conteúdo), era na verdade o plástico (o suporte), conforme questionado por Eduardo Vicente em Indústria da Música ou Indústria Do Disco? A questão dos suportes e de sua desmaterialização no meio musical (2012) e também discutido por Sérgio Amadeu da Silveira em A música na época de sua reprodutibilidade musical (in: PERPETUO; SILVEIRA, 2009, p. 30).

Grandes gravadoras passaram a primeira década do século XXI empenhadas em uma batalha infrutífera contra seus próprios clientes que, ingenuamente ou não, entendiam o download ilegal e o compartilhamento de música como uma prática regular, e não como um crime pelo qual poderiam ser punidos (KEEN, 2009; LESSIG, 2004; TAPSCOTT, 2009).

Hoje diversos artistas interagem de maneiras criativas e oportunas com esse ambiente de livre compartilhamento de conteúdo. O que muitos entendiam como vendas perdidas, um lucro em potencial que não havia sido obtido por causa do acesso gratuito e ilegal ao conteúdo, portanto uma prática deplorável que deveria ser combatida; passou, com o tempo, a ser considerada uma oportunidade de mercado. Grupos como O Teatro Mágico e Móveis Coloniais de Acaju cedem seus álbuns em formato digital gratuitamente para seus fãs, que depois acabam por financiar os artistas comprando ingressos para os shows, camisetas, versões especiais de CDs, LPs e outros produtos (DE MARCHI, 20I2, p. Io).

Ainda que o formato já tenha sido sugerido no final do século XX por Aram Sinnreich em Digital Music Subscriptions - Post Napster product formats (2000), só na segunda metade da década de 20 Io que os serviços de streaming ${ }^{6}$ de música por assinatura se fortaleceram. É um mercado no qual o download rende cada vez menos, segundo dados da International Federation for the Phonographic Industry (IFPI, 2OI7, p. 6) e as antigas lojas de discos tornam-se cada vez mais lojas de estilo, vendendo camisetas, vídeo games, bonecos e outros objetos (PERPETUO; SILVEIRA, 2009); e no qual a música passa a ser oferecida como um serviço, para um público-alvo que não obrigatoriamente a compra, mas a escuta (GURGEL, 20I6, p. 8). A música é "vaporizada", segundo Marcelo B. Conter (20I7), sendo consumida de maneira digital por ouvintes que não mais arquivam as canções em suas discotecas ou discos rígidos, consumindo-as diretamente por streaming.
6. Forma de distribuição de dados em fluxo, na qual o usuário reproduz o conteúdo sem guardar uma cópia em seu computador.

Para a maior fluidez do texto, os termos streaming e download são utilizados sem grifo nesta dissertação. 
7. Armazenamento de informações em servidores que podem ser acessados remotamente a qualquer momento, como Dropbox, Google Drive e iCloud.
Paralelamente à alteração na indústria musical, a fotografia e a produção audiovisual sofrem mudanças de paradigma propiciadas pelas novas possibilidades de produção e compartilhamento de conteúdo, desta vez por meio dos próprios artistas e de seu público.

Enquanto a comunicação como um todo traça um caminho de volta à oralidade na transmissão de informações, como é sugerido por Thomas Pettit em seu Parêntese de Gutenberg (PETTIT, 20II), as imagens seguem caminho similar. Desde a invenção da imprensa por Gutenberg, as informações eram apresentadas de forma centralizada e oficial pelas fontes ditas confiáveis - livros, jornais e revistas, por exemplo -, e as imagens eram distribuidas da mesma maneira, utilizando-se de fontes oficiais de conteúdo tanto informativo quanto de entretenimento. Hoje, segundo o autor, fecha-se o "parêntese" histórico e volta-se a um contexto em que tanto as informações quanto as imagens são produzidas e transmitidas de pessoa a pessoa, propagando-se de forma irregular e descentralizada.

A oralidade e proximidade propiciadas pelo contexto digital são amplificadas por diversas tecnologias e serviços, entre eles as tecnologias de nuvem ${ }^{7}$, as de transmissão de vídeo personalizado e ao vivo e o surgimento de plataformas populares para a difusão de música independente. Entre elas destaca-se o YouTube, serviço criado em 2005 para o compartilhamento de conteúdo em vídeo captado ou produzido pelos próprios usuários, que incentiva uma cultura participativa de uma audiência mais ativa do que passiva, que não se contenta em apenas assistir mas comenta, compartilha e produz seus próprios vídeos em resposta (BURGESS; GREEN, 2009, p. I4). A plataforma tinha mais de um bilhão de usuários únicos por mês no final de 20I4, contra roo milhões nas versões gratuitas de serviços de streaming de música como Deezer e Spotify (IFPI, 2015, p. 7).

Os videoclipes mudam fundamentalmente a partir das alterações nos meios em que são veiculados e dos equipamentos que possibilitam sua produção amadora. No contexto digital, a produção de conteúdo é facilitada pela acessibilidade - tanto em termos de preço quanto em simplicidade de uso - e pela melhoria da qualidade técnica de smartphones e câmeras semiprofissionais. Em contexto similar ao que culminou na criação da MTV nos anos 8o, que buscava alcançar um público que se distanciava do conteúdo musical, os vídeos de música produzidos pelos amadores 
- sejam eles público ou o próprio artista -, apresentam uma nova maneira de se comunicar a música, através da facilidade de distribuição de conteúdo pela Internet ${ }^{8}$. A produção dos videoclipes deixa de ser coordenada somente pelas gravadoras e emissoras de televisão, como na década de I980, mas sim pelos próprios músicos e seu público, num mercado orientado pelas vendas (BAUMAN, 2013, loc. IIo4; LIPOVETSKY; SERROY, 2OI5, loc. I432).

A partir de uma comparação do mercado da música no século XX com a situação atual e da posterior identificação dos pontos de atrito entre os mesmos, que causam a alteração na maneira de se produzir o material de divulgação dos artistas musicais, é objetivo deste trabalho identificar a importância da produção e do compartilhamento de conteúdo amador para a divulgação de artistas independentes, em especial no site de vídeos YouTube. Não mais uma produção confinada nas mãos de artistas e profissionais da imagem, mas agora também a músicos e todo o seu público versado em produzir seu próprio conteúdo, reproduzindo ideias, copiando alguns conceitos e criando outros próprios de maneira muito mais livre - e não obrigatoriamente pior - que os profissionais.

Para tal, foram analisados sete artistas independentes de maneira vertical. A decisão foi de priorizar o aprofundamento em uma pequena amostra, não obrigatoriamente representativa de todo o mercado, dentro do escopo da música independente, definida para o propósito desta dissertação no item 2.I. A análise dos artistas foi composta pelo cruzamento de quatro instâncias: os dados de faturamento de seus produtos, obtidos graças à autorização de cada artista por tratarem-se de dados sigilosos; as informações de execução pública de suas faixas em rádios e televisão, através do serviço Playax; a aplicação de pesquisa com o método Delphi para as impressões de cada artista sobre suas principais plataformas, mídias e objetivos; e a análise de seus canais do YouTube, comparando-os com os dados cruzados anteriormente.

Por último, foi proposto um experimento imagético com a participação do público de uma apresentação musical de um dos artistas analisados, cujos resultados foram comparados aos de um experimento similar realizado dez anos antes. Amadores separados por uma década foram convidados a compartilhar suas imagens produzidas em um show, e seus resultados colorem a análise previamente desenvolvida nesta dissertação. 


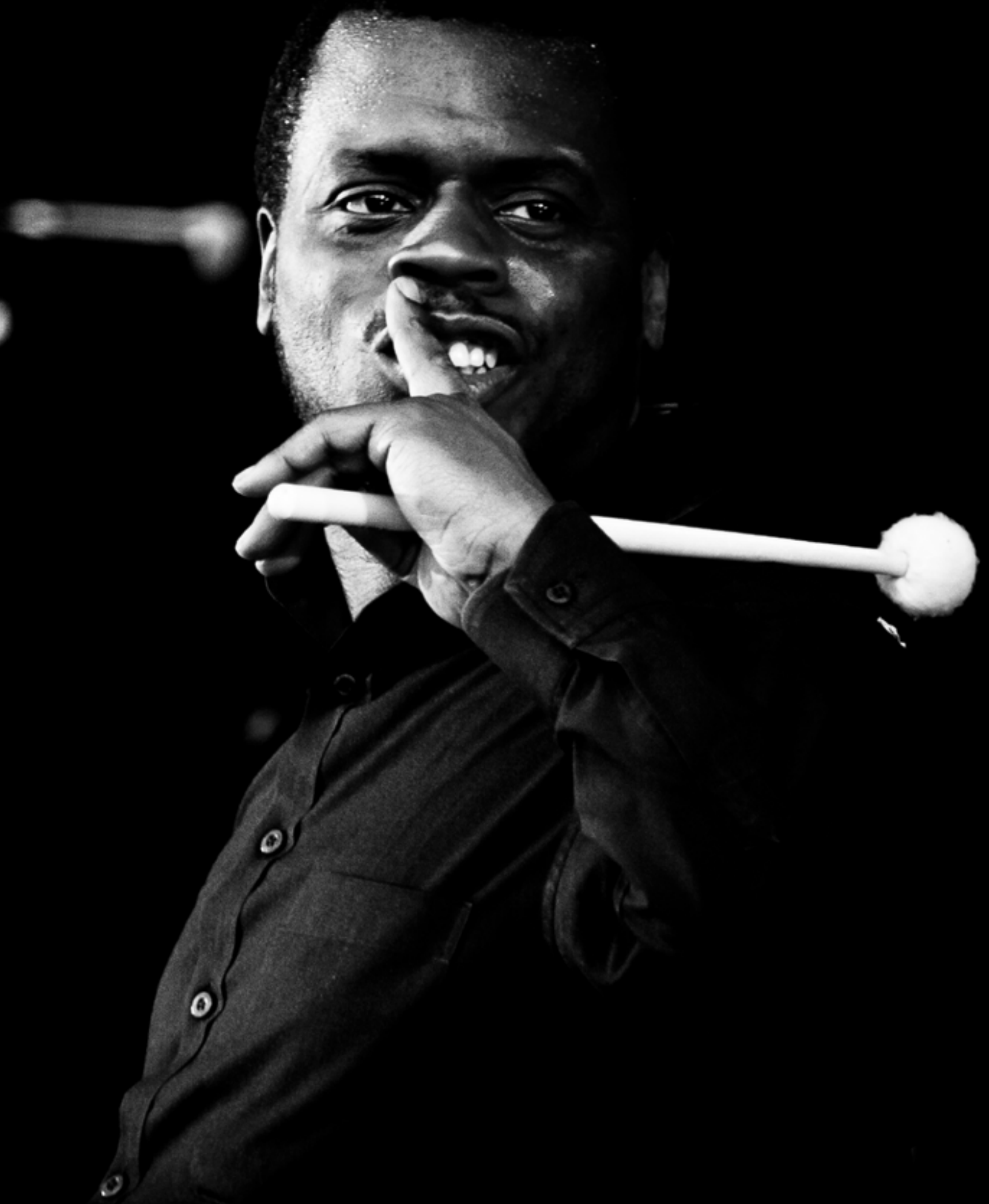




\section{CONSIDERAÇÕES \\ FINAIS}


153. Tradução livre do original em inglês "The word 'jazz' comes from the French jaser, to chatter. Jazz is, indeed, a form of dialogue among instrumentalists and dancers alike. Thus it seemed to make an abrupt break with the homogeneus and repetitive rhythms of the smooth waltz. (...) If jazz is considered as a break with mechanism in the direction of the discontinuous, the participant, the spontaneous and improvisational, it can also be seen as a return to a sort of oral poetry in which performance is both creation and composition. It is a truism among jazz performers that recorded jazz is 'as stale as yesterday's newspaper'. Jazz is alive, like conversation; and like conversation it depends upon a repertory of available themes. But performance is composition. Such performance insures maximal participation among players and dancers alike."

I54. Paráfrase livre do original em inglês: "Until recently our institutions and arrangements, social, political and economic, had shared a one-way pattern. We still think of it as "explosive," or expansive; and though it no longer obtains, we still talk about the population explosion and the explosion in learning. (...) Electricity does not centralize, but decentralizes."
A palavra "jazz" vem do francês jaser, que significa "tagarelice", ou "fofoca". O jazz é, de fato, uma forma de diálogo entre instrumentistas e bailarinos, que parece ter quebrado abruptamente com os ritmos homogêneos e repetitivos da valsa. [...]

Se o jazz é considerado uma quebra com o mecanismo padrão, na direção da descontinuidade, participação, espontaneidade e improvisação, ele também pode ser entendido como um retorno a um tipo de poesia oral na qual a performance é tanto criação quanto composição. É comum a afirmação entre músicos de jazz de que o jazz gravado é "tão obsoleto quanto o jornal de ontem". O jazz é vivo, como uma conversa; e assim como a conversa ele depende de um repertório de temas disponíveis. Mas a performance é composição. Essa performance assegura a máxima participação entre músicos e bailarinos. ${ }^{153}$ (MCLUHAN, 2001, p. 306)

Enjaulado em suas predefinições e na comunicação unidirecional e centralizada, o século XX simboliza o ápice do Parêntese de Gutenberg, apresentado por Thomas Pettit (2OII), em que a verdade estaria registrada nos livros e meios oficiais, e a palavra falada seria menos confiável. À medida que a produção de conteúdo se torna acessível para qualquer pessoa e as fontes se confundem, vive-se uma era de oralidade secundária, segundo Pettit: uma volta à comunicação medieval, em que a opinião daquele que é mais próximo vale mais do que outras possivelmente mais qualificadas.

A comunicação, hoje multidirecional, não pode mais ser compreendida como "explosiva" ou "expansiva", pois esses termos pressupõem a existência de um centro ${ }^{154}$ (MCLUHAN, 20oI, p. 39). Após o fechamento do Parêntese de Gutenberg, a comunicação flui por meios paralelos, a partir de múltiplas fontes que se entrelaçam e confundem. Interlocutores têm pouco conhecimento sobre a origem da informação que recebem, transitando pela vida sem diferenciar - ou se dar conta da necessidade de diferenciar - informações de fofocas. 
Ao mesmo tempo em que o fechamento do Parêntese confunde a confiabilidade das fontes de informações, ele abre espaço para o prossumidor de conteúdo (TOFFLER, I980); permite a autoria coletiva de obras em modo re-write (LESSIG, 2008); abre choruses ${ }^{155}$ para o improviso em uma comunicação mais parecida com o jazz do que com a música erudita. Jazz esse cuja essência, segundo Hobbsbawm, "é não ser uma música padronizada ou produzida em série" (I990, p. 3I).

Vilém Flusser (2008, p. I44), usa a relação entre a música de câmera e a música sinfônica como modelo, comentando a música de câmera como aquela em que os "músicos reunidos não visam tocar partitura mas sim improvisar sobre partitura (como se caracterizava música de câmera no Renascimento)". Flusser retrata uma música em que não há regente, e que os instrumentos, ao improvisar, "são simultaneamente emissores e receptores, individual e coletivamente, da mensagem que elaboram".

A volta à improvisação do Renascimento e a simultaneidade na emissão e recepção da música apresentadas por Flusser concordam com o fechamento do Parêntese de Gutenberg sugerido por Thomas Pettit. As canções voltam a ser transmitidas de forma oral, de público em público, através de seu conteúdo audiovisual compartilhado na Internet.

A música é desapropriada de seus autores por seus próprios fãs, que tomam a frente da transmissão de suas composições aos novos ouvintes. Canções tomam outros rumos nas vozes de seus releitores, que as passam adiante com pequenas alterações através de redes como o YouTube, assim como cantigas folclóricas eram passadas na era medieval (GURGEL; RADFAHRER, 2017, p. 15). Substituindo a venda central de partituras oficiais, a transmissão oral de uma melodia através da Internet aumenta um ponto a cada canto, e os próprios artistas produzem tutoriais em vídeo para fomentar essa apropriação.

A imagem segue o mesmo caminho, uma vez que, da mesma forma que a música, é produzida e difundida por amadores, cujos vídeos e fotografias tomam a frente na responsabilidade pelo conteúdo. Seu objetivo é o de reportar, registrar, informar. A paisagem imagética do indivíduo passa a ser aquela de seus vizinhos prossumidores, filtrada por sua própria concepção estética à medida em que formata os filtros de sua própria bolha (PARISER, 2оIra).
155. Forma da música para a improvisação, conceituada no item 5.2. 
Em 1984, Italo Calvino demonstrava sua preocupação com o excesso de imagens difundidas pela televisão. Ele se preocupava com o futuro da imaginação, que estaria comprometida por causa do excesso de imagens sem significado difundidas na mídia de massa:

Vivemos sob uma chuva ininterrupta de imagens; os media todo-poderosos não fazem outra coisa senão transformar o mundo em imagens, multiplicando-o numa fantasmagoria de jogos de espelhos - imagens que em grande parte são destituídas da necessidade interna que deveria caracterizar toda imagem, como forma e como significado, como força de impor-se à atenção, como riqueza de significados possíveis. Grande parte dessa nuvem de imagens se dissolve imediatamente como os sonhos que não deixam traços na memória; o que não se dissolve é uma sensação de estranheza e mal-estar. (CALVINO, I990, p. 73)

Mais de três décadas depois, é possível sugerir que seja, de fato, mais difícil para um indivíduo acessar a sua própria imaginação. Bombardeados por imagens padronizadas e cercados pelas paisagens estéticas de seus vizinhos de bolha, os prossumidores aparentam produzir imagens mais e mais similares às de seus colegas. Zygmunt Bauman sugere essa repetição ao questionar a necessidade de se pertencer a um grupo:

Os desejos e aspirações contraditórios que se fala aqui são o anseio de um sentido de pertencimento a um grupo ou aglomeração e o desejo de se distinguir das massas, de possuir um senso de individualidade e originalidade; o sonho de pertencimento e o sonho de independência; [...] o medo de ser diferente e o medo de perder a individualidade. (BAUMAN, 2013, loc. 273) 
Os prossumidores criam pequenas variações do tema ${ }^{156}$, imagens cada vez mais parecidas entre si, como foi atestado comparando as duas edições do experimento em apresentações musicais no capítulo 5. "O mundo se torna uma espécie de museu, repleto de objetos previamente encontrados em outras mídias ${ }^{157 "}$ diz McLuhan (200I, p. 215) em capítulo sobre a fotografia de Understanding Media, cuja primeira publicação foi em i964, já sugerindo a mesma reprodução de padrões pelos receptores da mídia de massa que Calvino sugeriu em i99o.

No século XX, os corredores da analogia do museu de McLuhan eram preenchidos por imagens que repetiriam as referências estéticas disseminadas pela mídia de massa. Após o fechamento do Parêntese de Gutenberg, todavia, essas imagens não são mais oriundas da grande mídia ou de um repositório central. A referência estética na qual os prossumidores se inspiram é aquela oferecida por seus vizinhos, que os rodeiam em seus filtros de bolha.

Por definição, um mundo construído a partir do que é familiar é um mundo em que não há nada para se aprender. Se a personalização é aguda demais, ela pode prevenir que entremos em contato com experiências e ideias que podem acabar com preconceitos e abrir nossas mentes, e portanto mudar a maneira pela qual pensamos sobre o mundo e sobre nós mesmos. ${ }^{158}$ (PARISER, 2011a, loc. 315)

Esta pesquisa partiu de uma hipótese: a de que o conteúdo amador poderia ser tão ou mais importante para a comunicação de um artista independente do que o conteúdo de videoclipes e fonogramas de produção profissional, em especial através do YouTube. Esse conteúdo é produzido em duas frentes: o público contribui com versões cover, homenagens, registros de shows, aulas de violão, karaokês e ainda certa fatia de conteúdo original republicado sem autorização; e os artistas contribuem com suas cenas de bastidores, ensaios, novas composições, apresentações ao vivo, participações, entremeados com seu conteúdo de lançamento comercial como videoclipes e faixas de álbuns.
I56. Conceito musical utlizado no item 5.2 como metáfora para imagens mais padronizadas, semelhantes entre si e também às imagens comuns de apresentações musicais presentes na mídia.

I57. Tradução livre de "The world itself becomes a sort of museum of objects that have been encountered before in some other medium".

I58. Tradução livre de trecho do livro The filter bubble: what the Internet is hiding from you: "By definition, a world constructed from the familiar is a world in which there's nothing to learn. If personalization is too acute, it could prevent us from coming into contact with the mind-blowing, preconception-shattering experiences and ideas that change how we think about the world and ourselves." 
A oralidade secundária, aquela que segue o fechamento do Parêntese de Gutenberg, apresenta um novo meio de se conhecer, ouvir, tocar e compartilhar música, especialmente através desse conteúdo amador. Artistas são apresentados através de seu próprio público, que relê e reescreve as canções a seu modo, registra e reporta seus acontecimentos com sua própria estética, e realimenta sua produção com seus próprios desejos.

Toda essa liberdade, todavia, revoluciona apenas a maneira de se produzir o conteúdo, mas não o conteúdo em si. Este último se percebe cada vez mais padronizado em pequenas vizinhanças, bolhas que não permitem que as novas e diferentes ideias atravessem seus filtros. Cada um dos sete artistas analisados nesta dissertação, ainda que correlacionados e com intersecções, apresenta uma persona diferente e pode ser representado em conjunto com seu público e alguns artistas similares como uma pequena vila. Vilarejo este no qual as ideias fluem livremente, convergindo público e artistas em prossumidores de um conteúdo prolixo, repleto de improvisos e da livre troca de informações, porém que pouco se comunica com as cidades vizinhas.

McLuhan apontava que a oralidade dos meios quentes nos levaria a uma aldeia global. Porém, por conta dos filtros de bolha, hoje prossume-se conteúdo em tribos digitais cada vez menores e mais filtradas pelos gostos e opiniões dos fãs nelas envolvidos. O público prossumidor formata-se como se fossem pequenos conjuntos de jazz entre os quais os integrantes não circulam, tocando choruses e mais choruses de improvisos repetitivos com os mesmos colegas, em vez de inspirar-se pelo som que é feito pelos outros conjuntos. 


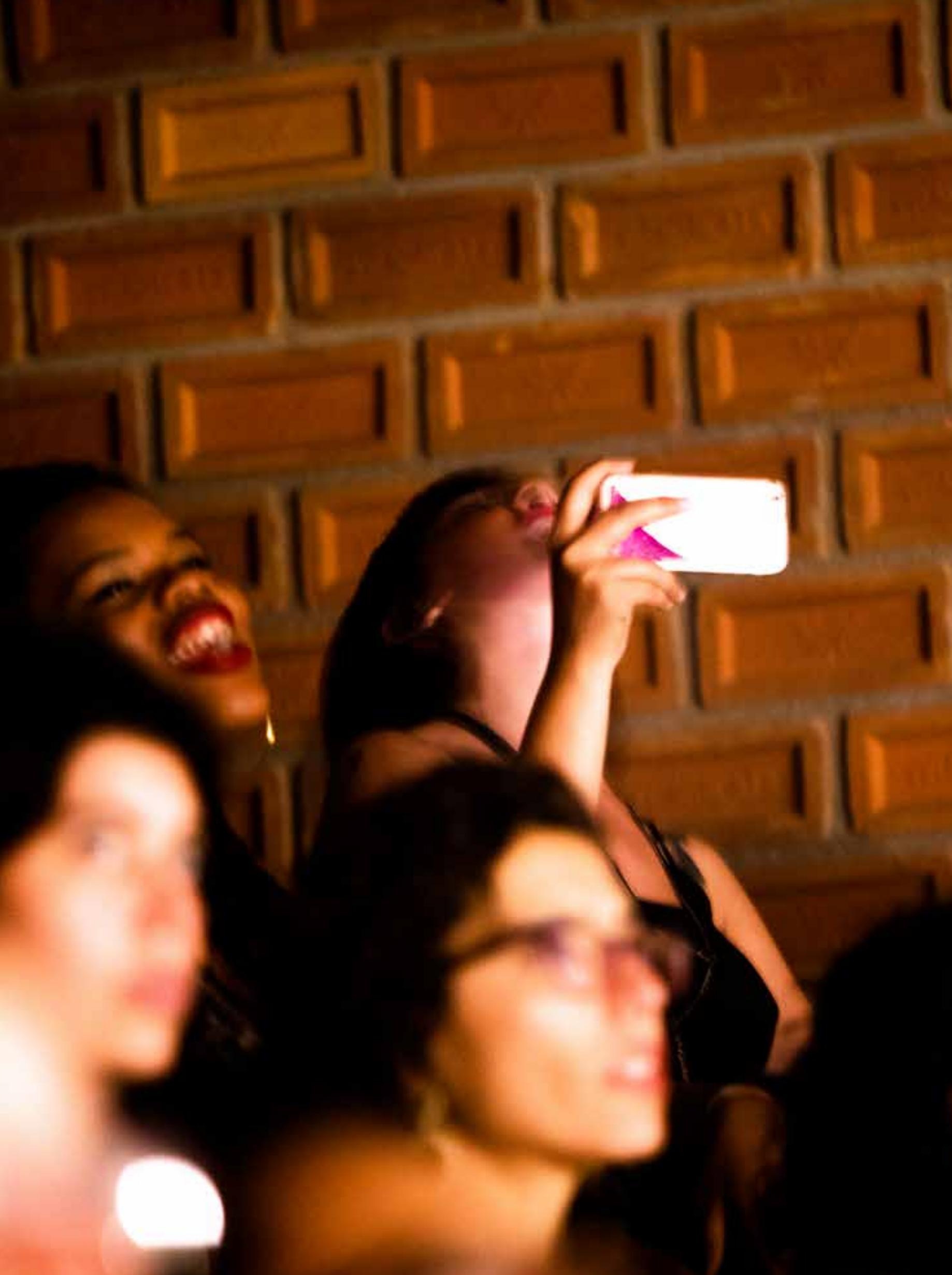







ABPD. Mercado Brasileiro de Música 20I4. Rio de Janeiro: Associação Brasileira de Produtores de Discos, 2015.

ABPD. Mercado fonográfico mundial e brasileiro em 20ı6. Rio de Janeiro: Associação Brasileira de Produtores de Discos, 20I7.

ACTIVATE. WSJD Live Conference. Think Again Tech and Media Outlook 2or6. Anais. Wall Street Journal, 20I5. Disponível em: <http://bit.ly/DG_activate>

AIGRAIN, Philippe. Sharing. Culture and the economy in the Internet age. Amsterdam: Amsterdam University Press, 20I2.

ANDERSON, Chris. Free : grátis : o futuro dos preços. Rio de Janeiro: Elsevier, 2009.

APPLE. Mastered for iTunes: Music as the Artist and Sound Engineer Intended. Disponivel em: <https://images.Apple.com/br/itunes/mastered-for-itunes/docs/mastered_for_itunes.pdfs. Acesso em 3I Jul 2017 .

BAUMAN, Zygmunt. A cultura no mundo líquido moderno. Rio de Janeiro: Zahar, 20I3. [Kindle] BENJAMIN, Walter. A obra de arte na era de sua reprodutibilidade técnica. Primeira versão. In: Magia e técnica, arte e política. São Paulo: Brasiliense, 1985. 
BERKMAN, The Berkman Center for Internet \& Society at Harvard. Rethinking Music: A Framing Paper. In: Rethinking Music: A Briefing Book. Cambridge: The Berkman Center for Internet \& Society at Harvard, 20II. p. 7-26.

BITTAR, Carlos Alberto. Direito de autor. São Paulo: Forense Universitária, 2003.

BM\&A. Pesquisa sobre o músico brasileiro. Disponível em: <http://bma.org.br/noticia/pesquisa-sobre-o-musico-brasileiro-42I>. Acesso em: 4 jun. 2017.

BURGESS, Jean.; GREEN, Joshua. YouTube e a revolução digital: como o maior fenômeno da cultura participativa transformou a mídia e a sociedade. São Paulo: Aleph, 2009.

BUSSAB, Mauricio. Como funciona o streaming de música para os artistas? Disponível em: $<$ http://bit.ly/DG_tratore-streaming>. Acesso em: Io jan. 20I6a.

Julho/2or5: Por que demoramos sete anos para quebrar um recorde. Disponível em: <http://bit.ly/DG_tratore2or5>. Acesso em: ıo jan. 2016b.

CALADO, Carlos. O Jazz como espetáculo. São Paulo: Perspectiva : Secretaria de Estado da Cultura, I990.

CALVINO, Italo. Seis propostas para o próximo milênio. São Paulo: Companhia das Letras, I990.

CONTER, Marcelo B. A vaporização da música. Anais do $40^{\circ}$ Congresso Brasileiro de Ciências da Comunicação, p. I-I5, 2017.

COUPER, Mick P. The future of modes of data collection. Public Opinion Quarterly, v. 75, n. 5 SPEC. ISSUE, p. 889-908, 20II.

CUKIER, Daniel. Playax, plataforma de desenvolvimento de audiência para profissionais da música. Disponível em: <http://www.playax.com.br>. Acesso em: I jan. 2017.

DE MARCHI, Leonardo. Transformações estruturais da indústria Fonográfica no brasil 19992009: Desestruturação do mercado de discos, novas mediações do comércio de fonogramas digitais e consequências para a diversidade cultural no mercado de música. Rio de Janeiro: Tese de doutorado. Universidade Federal do Rio de Janeiro, 2оI.

Inovação e institucionalização na indústria fonográfica brasileira: Um estudo de caso as estratégias de negócio de músicos autônomos no entorno digital. Revista de Economia Política e las Tecnologias de la Información y de la Comunicación, p. I-22, 2012.

DEBORD, Guy. A sociedade do espetáculo. Rio de Janeiro: Contraponto, 1997.

DEBRAY, Regis. As três idades do olhar. In: Vida e morte da imagem. Petrópolis: Vozes, 1994.

DINES, David. Guerra dos volumes: o que muda com o streaming? Disponível em: $<$ https:// tratore.wordpress.com/2017/o6/ı2/guerra-dos-volumes-o-que-muda-com-o-streaming/>. Acesso em: 19 jun. 2017. 
ECAD. Mudança na regra de distribuição do segmento de Músico Acompanhante. Rio de Janeiro: ECAD, 2012.

Nova mudança na regra de distribuição do segmento de Músico Acompa-

nhante. Rio de Janeiro: ECAD, 2014.

FACEBOOK. News Feed FYI: Balancing Content from Friends and Pages. Disponível em: $<$ http://bit.ly/DG_fbnewsfeed $>$. Acesso em: I3 fev. 2016.

FLANAGAN, Andrew. The MP3 Is Officially Dead, According To Its Creators. Disponivel em: <http://www.npr.org/sections/therecord/2017/05/II/527829909/the-mp3-is-officially-dead-according-to-its-creators>. Acesso em: I8 jul. 2017.

FLICHY, Patrice. Internet, um mundo para os amadores. In: Redes digitais: um mundo para os amadores. Santa Maria: FACOS - UFSM, 2016.

FLUSSER, Vilém. Filosofia da caixa preta. Rio de Janeiro: Relume Dumará, 2002.

O universo das imagens técnicas. São Paulo: Annablume, 2008.

FMC. Music + Money Quiz. Washington: Future of Music Coalition, 20I4.

Artist Revenue Streams Handout. Washington: Future of Music Coalition, 2015.

Artist Revenue Streams. Disponível em: <http://arsdatafutureofmusic.org/>.

Acesso em: Io jan. 2016.

FUNG, Anthony Y. H. The iTunization of pop: Mobile music and youth social networks. Perfect Beat, v. 15, n. I, p. 23-43, 2014.

GEIST, Monica R. Using the Delphi method to engage stakeholders: A comparison of two studies. Evaluation and Program Planning, v. 33, n. 2, p. I47-I54, 2010.

GOOGLE. How Google Fights Piracy. Mountain View: Google, 2016.

GREENBURG, Zack O'Malley. Revenge Of The Record Labels: How The Majors Renewed Their Grip On Music. Forbes, abr. 20I5.

GURGEL, Dani. Fotografia e música - do vinil ao mp3, do filme ao celular. Trabalho de conclusão de curso. Universidade de São Paulo, 2007.

so em 3i Jul 20I7.

Música de Graça. Disponível em: <http://www.musicadegraca.com.br>. Aces-

O Novo Público Da Indústria Musical : Aquele Que Compra Ou Aquele Que

Escuta? Signos do consumo, v. 8, n. 2, p. 44-53, 2016.

Outro Som. Brasil: Da Pá Virada, 2018. 
GURGEL, Dani; RADFAHRER, Luli. "Pra Você Dar o Nome": uma canção ressignificada através dos covers de fãs no YouTube. Anais do $40^{\circ}$ Congresso Brasileiro de Ciências da Comunicação, 2017.

HOBBSBAWM, Erick J. História Social do Jazz. São Paulo: Triunfo, I990.

HOLZBACH, Ariane. Convergência na cultura musical: O videoclipe como sintoma da "revolução" analógica dos anos 80. Contemporânea, v. I2, n. 2, p. 340-359, 2014.

O Video Music Awards e a consolidação do videoclipe como gênero. Fronteiras - estudos midiáticos, v. I6, n. 2, p. 9I-IO3, 2013.

IFPI. Digital Music Report 20I4. Zurich: International Federation of the Phonographic Industry, 20I4.

nographic Industry, 2015.

Digital Music Report 2015. Zurich: International Federation of the Pho-

Global music report. Zurich: International Federation of the Phonographic Industry, 2016.

Global Music Report 2017. Zurich: International Federation of the Phonographic Industry, 2017.

IMMINK, Kees A. S. Shannon, Beethoven, and the Compact Disc. IEEE Information Theory Newsletter, v. December, n. December, p. 42-46, 2007.

INGHAM, Tim. Adele's 25 just went platinum in $\mathbf{2 4}$ hours. Music Business Worldwide. Disponível em: <http://www.musicbusinessworldwide.com/adeles-25-just-went-platinum-in-24-hours/>. Acesso em: 30 abr. 20i6a.

What Taylor Swift vs. Apple tells us about artist power and a music business going cheap. Music Business Worldwide. Disponível em: <http://bit.ly/DG_mbw2>. Acesso em: 30 jul. $2017 b$.

Adele has done it: 25 records biggest ever first week sales in US market. Music Business Worldwide. Disponível em: <http://bit.ly/DG_mbwi>. Acesso em: Io jan. 20r6c.

I6bn reasons why Adele's streaming snub paid off. Music Business Worldwi-

de. Disponível em: <http://www.musicbusinessworldwide.com/I6bn-reasons-why-adeles-streaming-snub-paid-off/>. Acesso em: 30 abr. 20i6a.

YouTube: We'd love to tell you what we're paying artists... if we were allowed. Music Business Worldwide. Disponivel em: <http://www.musicbusinessworldwide.com/youtube-wed-tell-paying-artists-allowed/>. Acesso em: 30 jul. $2017 \mathrm{~b}$.

Music subscriptions exploded in the US in 2016, as market generated $\$ 7.7 \mathrm{bn}$. Music Business Worldwide. Disponivel em: <http://www.musicbusinessworldwide.com/music- 
-subscriptions-exploded-in-the-us-in-20I6-market-generated-7-7bn/>. Acesso em: 30 jul. 20I7a.

Japan's recorded music business grew last year (but only just). Music Business Worldwide. Disponível em: <http://www.musicbusinessworldwide.com/japans-recorded-music-business-grew-last-year-just/>. Acesso em: 30 jul. 20I7b.

JANOTTI JÚNIOR, Jeder.; SOARES, Thiago. O videoclipe como extensão da canção: apontamentos para análise. Revista Galáxia, v. I5, p. 9I-I08, 2008.

JENKINS, Henry. Convergence Culture: where old and new media collide. New York: New York University, 2006.

O que aconteceu antes do YouTube? In: BURGESS, J.; GREEN, J. (Eds.). YouTube e a revolução digital. São Paulo: Aleph, 2009.

KEEN, Andrew. O Culto do Amador: como blogs, MySpace, YouTube e a pirataria digital estão destruindo nossa economia, cultura e valores. Rio de Janeiro: Jorge Zahar, 2009.

KELLOG, John P. Introduction to the Music Business. Boston: Berklee College of Music \& edX, 2015. KISCHINHEVSKY, Mauricio; VICENTE, Eduardo; DE MARCHI, Leonardo. Música infinita: serviços de streaming como espaços híbridos de comunicação e consumo musical. Compós, p. I-I9, 2015.

LEMOS, Ronaldo. Creative commons, mídia e as transformações recentes do direito da propriedade intelectual. Revista Direito GV, 2005.

LESSIG, Lawrence. Free Culture. New York: The Penguin Press, 2004. v. 53

Penguin Books, 2008.

Remix: Making Art and Commerce Thrive in the Hybrid Economy. London:

LIPOVETSKY, Gilles.; SERROY, Jean. A estetização do mundo - Viver na era do capitalismo artista. São Paulo: Companhia das Letras, 2015. [Kindle]

MACHADO, Arlindo. A Televisão levada a sério. São Paulo: Editora Senac, 2000.

As imagens técnicas: da fotografia à síntese numérica. In: Pré-cinema e pós-

-cinemas. Campinas: Papirus, 2002.

MANOVICH, Lev. Instagram and contemporary image. New York: manovich.net, 2016.

MCLUHAN, Marshall. Understanding Media. New York: Routledge Classics, 200I.

MUANIS, Felipe. MTV Brasil e o Ocaso do Fluxo. Novos Olhares, v. 3, n. 2, p. 59-69, 2015.

NPR. The Loudness Wars: Why Music Sounds Worse. Disponível em: <http://www.npr. org/2009/I2/3I/I221I4058/the-loudness-wars-why-music-sounds-worse>. Acesso em: I8 jul. 2017. 
OFUGI, Fabricio. A Internet livre como meio do músico independente. Dissertação de Mestrado. São Paulo: Faculdade Cásper Líbero, 20II.

PANAY, Panos. Rethinking Music: The Future of Making Money as a Performing Artist. Rethinking Music: A Briefing Book, p. 57-64, 20II.

PARISER, Eli. The Filter Bubble. What the Internet Is Hiding From You. New York: The Penguin Press, 20ira.

Acesso em: I jan. 2015b.

Beware online "filter bubbles". Disponível em: <http://bit.ly/DG_pariser>.

PEGORER, Luciana. Streaming é execução pública? São Paulo: ABMI, 2016.

PEREIRA, Raul. E.; SILVA, Wagner Souza e. Pequena História da Fotografia nas Redes Sociais. Passagens, v. 8, n. 2, p. 206-219, 2017.

PERPETUO, Irineu Franco; SILVEIRA, Sergio Amadeu da. O Futuro da Música Depois da Morte do CD. São Paulo: Momento Editorial, 2009.

PETTIT, Thomas. Thomas Pettitt on the Gutenberg Parenthesis. Disponivel em: <http://bit.ly/ DG_pettit>. Acesso em: 5 jan. 2018.

POLIMENO, Juliano. Remuneração dos Artistas no Streaming. Disponível em: <http://bit.ly/ DG_playax>. Acesso em: Io jan. 2016.

SADIE, Stanley. Dicionário Grove de Música: edição concisa. Rio de Janeiro: Jorge Zahar, 1994.

SILVEIRA, Sergio Amadeu da. Arquiteturas em disputa: ativistas $\mathrm{P}_{2} \mathrm{P}$ e a indústria da intermediação. Revista de Economía Política de las Tecnologías de la Información y Comunicación, v. XI, n. I, 2009.

SINNREICH, Aram. Digital Music Subscriptions - Post Napster product formats. New York: Jupiter Research, 2000.

Configurable culture. Mainstreaming the remix, remixing the mainstream. Tese de Doutorado. University of Southern California, 2007.

Arista Records LLC, et al. v. Lime Group LLC, et al. Expert report of Aram Sinnreich. Montclair: Aram Sinnreich, 20II.

TAPSCOTT, Don. Grown Up Digital: How The Net Generation is Changing Your World. New York: McGraw Hill, 2009.

THOMSON, Kristin; COOK, Jean. Artist Revenue Streams: A Multi-Method Research Project Examining Changes in Musicians' Sources of Income. In: RETHINKING MUSIC A Briefing Book. The Berkman Center for Internet \& Society At Harvard University, 20II. p. 87-Ioo. 
TOFFLER, Alvin. The Third Wave. New York: William Morrow and Company, Inc., 1980.

UBC. Guia do Associado. Rio de Janeiro: União Brasileira de Compositores, 2016.

VENÍCIO, Walter. Entrevista concedida para esta pesquisa. São Paulo, 2017.

VICENTE, Eduardo. A vez dos independentes (?): um olhar sobre a produção musical independente do país. Ecompós, p. 19, 2006.

Indústria da Música ou Indústria Do Disco? A questão dos suportes e de sua desmaterialização no meio musical. Rumores, n. I2, p. I-I6, 2012.

\subsection{JURISPRUDÊNCIA}

BRASIL. Supremo Tribunal Federal. Recurso Especial No 1.559.264. Relator: Ministro Ricardo Villas Bôas Cueva. Pesquisa de Jurisprudência, Acórdãos, 22 Março 2017. Disponível em: $<$ https://ww2.stj.jus.br/processo/pesquisa/?tipoPesquisa=tipoPesquisaNumeroUnico\&ter$\mathrm{mo}=01749584520098$ I $9000 \mathrm{I} \&$ totalRegistrosPorPagina $=40 \&$ aplicacao=processos.ea $>$. Acesso em: 3г Mai 2017 .

RIO DE JANEIRO. Tribunal de Justiça. Processo: oir6365-I3.20I5.8.I9.ooor. Relator: Juíza Maria Cristina de Brito Lima. Pesquisa de Jurisprudência, Decisão de 22 de Novembro de 20r6. Disponivel em: < http://www4.tjrj.jus.br/consultaProcessoWebV2/consultaProc.do?v=2\&FLAGNO$\mathrm{ME}=\& \mathrm{back}=\mathrm{I} \&$ tipoConsulta=publica\&numProcesso=2015.00I.IO2I44-7>. Acesso em: 3 I Mai 2017. 
Contato da autora:

contato@danigurgel.com.br http://www.danigurgel.com.br 